\title{
Lumbar mass as the presentation form of a tuberculous spondylodiscitis
}

\author{
Marcílio Diogo de Oliveira Barbosa', Rodrigo Sodré Calheiros da Silva', \\ Flávio Assad Garcia', Marcus André Acioly ${ }^{1,2,3}$
}

A 32-year-old man presented with an increasing lumbar mass which was initially noted 5 months before admission. He reported a 4-month history of minor low back pain radiating to his right leg and night sweats. Physical examination revealed only a left painful lower lumbar tender mass. Lumbar MRI demonstrated spondylodiscitis over L3-L4 complicated by epidural abscess, as well as bilateral psoas abscesses spreading through the posterior abdominal wall on the left side (Figure). The patient was then submitted to a L3 hemilaminectomy with biopsy and surgical debridement of the L3-L4 intervertebral disc space. Histopathological examination showed tuberculous granuloma and the patient was properly treated.
After break out of the purulent material from the vertebral body, a psoas abscess may develop and expand through the path of least resistance ${ }^{1,2}$. The presentation thus depends on the anatomical path of abscess' dissemination ${ }^{1}$. In this regard, a lower lumbar mass may occur when the purulent material leaves the psoas above the iliac crest extending posteriorly through the inferior lumbar triangle or Petit's triangle.

\section{REFERENCES}

1. Millar TM, McGrath P, McConnachie CC. Tuberculosis of the spine presenting with a cold abscess through the lumbar triangle of Petit. Clin Anat 2007;20:329-331.

2. Sanal HT, Kocaoglu M, Sehirlioglu A, Bulakbasi N. A rare cause of flank mass: psoas abscess due to extensive primary thoracolumbar tuberculous spondylodiskitis. AJNR Am J Neuroradiol 2006;27:1735-1737.
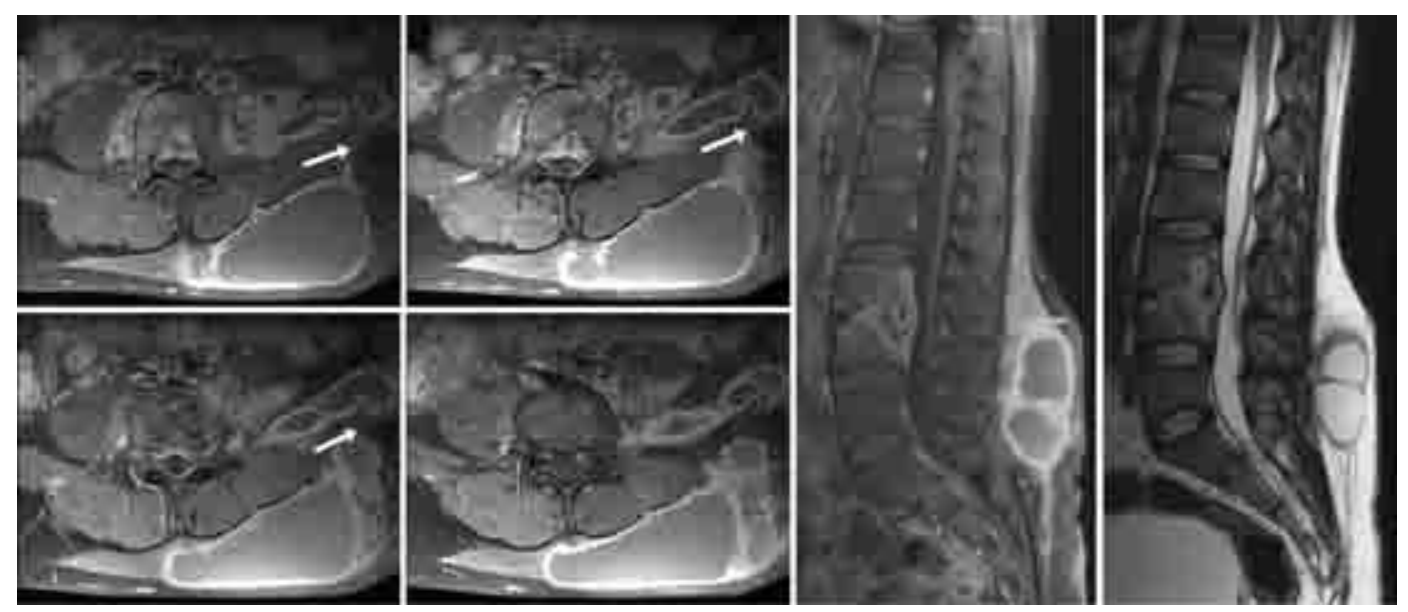

Figure. Sequential axial and sagittal gadolinium-enhanced T1-weighted (left) and sagittal T2-weighted (right) MR images showing the continuous spectrum of the disease from the intervertebral disc to the subcutaneous space through the posterior abdominal wall (white arrows).

\section{MASSA LOMBAR COMO FORMA DE APRESENTAÇÃO DE ESPONDILODISCITE TUBERCULOSA}

'Division of Neurosurgery. Andaraí Federal Hospital, Rio de Janeiro RJ, Brazil; ${ }^{2}$ Department of Surgical Specialities, Division of Neurosurgery. Pedro Ernesto University Hospital. State University of Rio de Janeiro, Rio de Janeiro RJ, Brazil; ${ }^{3}$ Department of Neurology, University of São Paulo, São Paulo SP, Brazil.

Correspondence: Marcus André Acioly - Rua Leopoldo 280 - 20541-170 Rio de Janeiro RJ - Brasil. E-mail: marcusacioly@yahoo.com.br

Received 23 March 2011, received in final form 16 April 2011. Accepted 26 April 2011. 